\title{
Assessment of the impact of climate change on intensity-duration-frequency (IDF) equations in Benin City, Nigeria
}

\begin{abstract}
The impact of climate change on the hydrologic system is widely recognized to be geographic location -specific, thus each geographic location should be assessed for the plausible impacts of climate change. Consequently, this research was conducted to assess the impact of climate change on Intensity -Duration-Frequency equations in Benin City, Nigeria. Trend analysis was performed using Mann-Kendall test while the Sen's slope method was used to estimate the magnitude of the change. The main results may be summarized as

i. Statistically insignificant negative(downward) trends were observed for annual rainfall intensities for durations of 10 to 30 - minute;

ii. Both statistically insignificant downward and upward trends were obtained for durations above 45-minute except for 540 -minute duration where a statistically significant positive trend was obtained.

All statistical tests were conducted at 5\% significance level. Since the statistical insignificant negative (downward) trends were obtained for rainfall durations of 10 - 30-minute, which is usually the range for inlet time generally applied for design of urban drainage systems. It implies therefore, that climate will pose negligible impacts on flood risk. Consequently the 34-year annual rainfall intensity series(the longest available) was used to develop IDF equations of the Wisner's equation type for return periods of 5- to 100-year. The explanatory power and accuracy of the IDF equations may be represented by the following inequalities; $0.40 \leq \mathrm{R} 2 \leq 0.972 ; 2.55 \leq \mathrm{SEE} \leq 4.31$; $2.34 \leq \mathrm{RMSE} \leq 3.96 ; 0.044 \leq \mathrm{RSR} \leq 0.056 ; 1.93 \leq \mathrm{MAE} \leq 2.96$. These inequalities indicate that the equations are very good for estimation of storm runoff and for design of drainage systems, and as input for urban drainage simulation modelling systems such as SWMM model.
\end{abstract}

Keywords: Benin city, climate change, IDF, SWMM model, Wisner's equation

\section{Introduction}

Rainfall is a fundamental component of the hydrologic cycle and its availability may have enormous impacts on the environment and human society. The hydrologic cycle may be described quantitatively in terms of the atmosphere and land phase interactions using the hydrologic equation. Climate change has the potential to amplify the natural climate variability throughout the inter-connected climate and hydrologic systems. ${ }^{1}$ Assessing the potential changes in extreme precipitation events has therefore become one of the most important research concerns in hydrological risks analysis and engineering designs. ${ }^{2}$ The change therefore will necessitated reviewing and updating the rainfall characteristics in the form of IDF relationship. The IDF relationship is one of the most commonly used tools in water resource engineering either for planning, design and operating of water resources project, against floods. ${ }^{3}$ The use of IDF curves and equations in the design of water management infrastructure is a standard practice in most countries. ${ }^{4,5}$

Bell ${ }^{6}$ derived generalized rainfall-duration-frequency relationship for the United States which requires only 10 years 1-hour rainfall depth. In the United Kingdom, the establishment of IDF dates back to $1932 .^{7}$ The 2005 Asian Pacific FRIEND held at Kuala Lumpur, Malaysia focused on intensity frequency Duration and Flood Frequencies determination. Most countries in South East Asia and the Pacific re-iterate the importance of IDF and adopt it as a tool for
Volume 3 Issue 2 - 2019

\section{Itolima Ologhadien}

Department of Civil Engineering, Rivers State University, Port Harcourt, Nigeria

Correspondence: Itolima Ologhadien, Department of Civil Engineering, Rivers State University, Port Harcourt, Nigeria, Email itolimaologhadien6@gmail.com, itolima2000@yahoo.com

Received: March 02, 2019| Published: March I5, 2019 determination of flood frequencies. Traditionally, IDF studies was conducted based on historical data collated at a given weather stations and the IDF curves developed were updated periodically when new data is available. Stationarity is a fundamental concept in traditional hydrologic frequency analysis(HFA), which implies that any variable (e.g. annual stream flow, annual flood peaks, or annual maximum precipitation) has a time-invariant probability density function (pdf) whose statistical properties (mean, standard deviation etc.) can be estimated from historic data. ${ }^{2,8}$ The notion of stationarity which has been the foundation basis for design, planning, management of water resources system and studies is now being challenged. ${ }^{9}$

Consequently, water resources engineers are in dare need of hydrological tools that would account for nonstationarity nature of climate change. Ganguli \& Coulibaly ${ }^{10}$ observed that "despite apparent signals of non-statationarity in precipitation extremes in all locations, the stationary vs non-stationarity models do not exhibit any significant differences in the design of storm intensity, especially for short recurrence intervals (up to 10 years)". Also they observed that the signature of non-stationarity in rainfall extremes do not necessarily imply the use of non-stationarity IDF for design considerations.

The traditional way of studying the impacts of climate change at catchment scale involves downscaling the outputs of global circulation models (GCMs) from which location specific impacts such as IDF, etc are derived. ${ }^{11}$ Currently, there is no standard or accepted 
methodology to derive IDF curves or equations for future climate conditions. ${ }^{12,13}$ In this study, the observed trends of precipitation and intensity and magnitude for the period 1965 to 2000 were used to extrapolate statistically current IDF curves to infer future climate. Goori Bi et al., ${ }^{13}$ and Olsson et al., ${ }^{14}$ used this method to extrapolate current IDF curves for Arzika, Sweden. Denault et al., ${ }^{15}$ also used this method for Vancouver Canada, and Guo ${ }^{16}$ applied the same approach for Charlottenlund, Denmark, to predict extreme precipitation for the future. The main limitation of the approach is the assumption that current trends in rainfall intensity will remain the same in the future. ${ }^{12,15}$ The impact of future climate on urban discharges will be modeled using a probabilistic approach such as the rational formular method, SWMM hydrological model etc., that will convert the updated precipitation events into a design flood event.

The objective of the study is to assess the trends in rainfall intensities for various durations in Benin City under the changing climatic conditions. The paper is organized follows; the introduction section presents a concise background information on climate change, hydrologic systems, and IDF. Section 2 contains the materials and methods comprising a brief description of data and study area, (i) non-parametric trend analysis using Mann-Kendall tests, Thiel-sen estimator to rainfall intensity, statistical analysis of rainfall of various durations and development of IDF equation/curves and evaluation of IDF models efficiency. Section 3 presents the results and discussion comprising derivation of IDF, trend analysis of rainfall intensities, future IDF projections and urban drainage and evaluation of models efficiencies. Section 4 contains the conclusion and recommendation.

\section{Materials and methods}

\section{Data and study area}

Benin City is an ancient town in Nigeria. It is located between latitude $06^{\circ} 10^{\prime} \mathrm{N}$ and Longitude $05^{\circ} 36^{\prime} \mathrm{E}$. The altitude is $79.3 \mathrm{~m}$ above mean sea level. The rainfall data from meteorological Station at Benin City International Airport are used, which has good quality dataset with reliable data and adequate record-length of 34 years (1965 2000).

\section{Detection of trend in rainfall intensity}

The statistical significance of a trend can be detected by means of statistical tests such as the rank-based non-parametric Mann-Kendall test. The Man-Kendall test is used for trend detection and Sen's Slope method is use for the determination of magnitude of change. The rainfall intensities are ranked according to time and then each data point is successively treated as a reference data point and is compared to all data points that follow in time. ${ }^{17}$ The Mann-Kendall method is based on one statistic $\mathrm{S}$. The statistic $\mathrm{S}$ is computed by comparing all possible pairs of values $\left(\mathrm{I}_{\mathrm{i}}, \mathrm{I}_{\mathrm{j}}\right)$ in the data set and scoring as follows:

If $I_{i}<I_{j}$, is scored +1 ; If $I_{i}>I_{j}$, is scored -1 and $I_{i}=I_{j}$ is assigned 0 , where $I_{i}$ is the value of rainfall intensity at time (t-1) and $I_{j}$ is value at time ( $\mathrm{t}$ ). After scoring each pair in this way and adding up the total to get the Mann-Kendall statistics (S). The Mann-Kendall statistics S is calculated as:

With

$$
S=\sum_{i=1}^{N-1} \sum_{j=i+1}^{N} \operatorname{Sign}\left(I_{j}-I_{i}\right)
$$

$$
\operatorname{Sign}\left(I_{j}-I_{i}\right)=1 \text { If }\left(I_{j}-I_{i}\right)>0
$$

$$
\begin{array}{lll}
\operatorname{Sign}\left(I_{j}-I_{i}\right)=0 & \text { If }\left(I_{j}-I_{i}\right)=0 \\
\operatorname{Sign}\left(I_{j}-I_{i}\right)=-1 & \text { If }\left(I_{j}-I_{i}\right)<0
\end{array}
$$

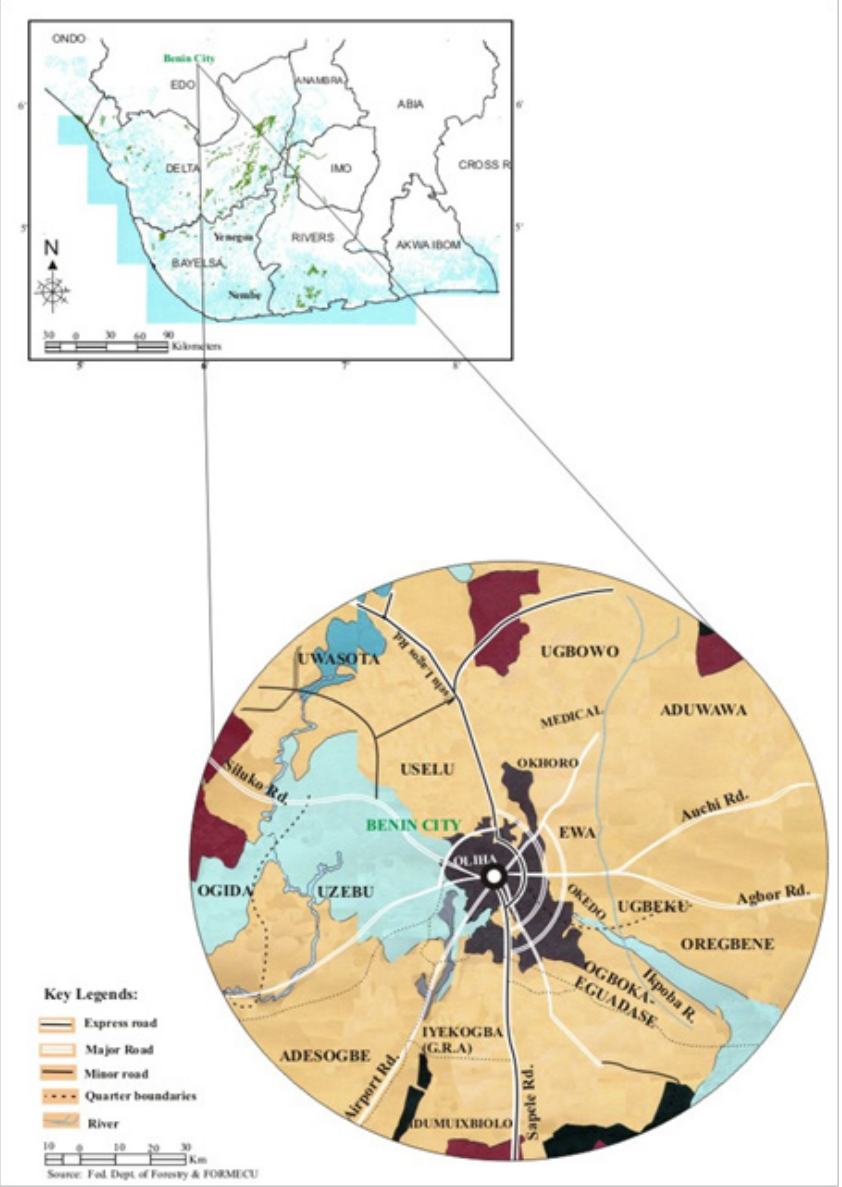

A positive value of $S$ is indicative of an upward trend and a negative value of $\mathrm{S}$ implies a decreasing trend, where zero is suggestive of no-trend. ${ }^{18,19}$ For independent, normally distributed random variables having no-tied data values and zero mean. The variance is given by:

$$
\operatorname{Var}(S)=\frac{N(N-1)(2 N+5)}{8}(3)
$$

When some data values are tied, the correction to $\operatorname{Var}(\mathrm{S})$ is:

$$
\operatorname{Var}(S)=\frac{N(N-1)(2 N+5)-\sum_{i=1}^{g} t_{j}(t j-1)\left(2 t_{j}+5\right)}{18}
$$

Where $\mathrm{N}$ is the sample size, g represents the number of groups of ties in the data set (if any); and $t_{j}$ is the number of ties in the $j^{\text {th }}$ group of ties. To evaluate the significance of the trend, when the samples size (n) is greater than 10 ; the test statistic $\mathrm{S}$ is transformed to define a standard normal $(\mathrm{Z}) . \mathrm{Z}$ statistic as follows;

$$
\begin{aligned}
& Z=\frac{(S-1)}{\sqrt{\operatorname{Var}(S)}} \quad \text { If } S>0 \\
& Z=0 \quad \text { If } S=0 \\
& Z=\frac{(S-1)}{\sqrt{\operatorname{Var}(S)}} \quad \text { If } S<0
\end{aligned}
$$


A trend is apparent in the time series when the absolute value of the Z-statistic computed in Equation 5 is greater than $Z_{a / 2}=F^{-1}(1-a / 2)$ for a defined significance level () and thus the null hypothesis (not trend) is rejected. ${ }^{18}$ At the $5 \%$ significance level, the null hypothesis is rejected as $|Z|>1.96$.

\section{Estimation of the magnitude of trend}

The Theil-Sen trend line is a non-parametric in which the median pairwise slope is combined with the medium values and their corresponding dates to construct the final trend line. In this way, the Theil-Sen line estimates the change in median slope over time and not the mean as in linear regression. Consequently, the Theil-Sen tried line is a non-parametric alternative to linear regression which can be used in conjunction with the Mann-Kendal test. In computational procedure, the slope estimates of $\mathrm{N}$ pairs of data are first computed by;

$$
I_{i, j}=\frac{I_{j}-I_{i}}{j-i} \text { for } i=1, \ldots n(6)
$$

Where $I_{j}$ and $I_{i}$ use the rainfall intensities at time $I$ and $j_{(j-k)}$ respectively. With a sample size $\mathrm{N}$. There should be a total of $\mathrm{N}=\mathrm{n}(\mathrm{n}$ -1)/2 such pairwise estimates of $I_{i . j}$. The Theil-Sen's Estimator of the slope is the median of the $\mathrm{N}$ values of $\mathrm{I}_{\mathrm{i}, \mathrm{j}}$. The $\mathrm{N}$ value of $\mathrm{I}_{\mathrm{i}, \mathrm{j}}$ are ranked in ascending order, smallest to the largest and the Sen's estimator is calculated as:

$$
I_{\text {med }}=\mid \begin{array}{ll}
I_{[(n+1) / 2]} \quad \text { If } n \text { is odd } \\
\frac{I_{[n / 2]}+Q_{[(n+2) / 2]}}{2} & \text { If } n \text { is even }
\end{array}
$$

The sign of $I_{i, j}$ reflects the data trend, while its numerical value indicates the steepness of the trend. Positive or negative slope is obtained as upward (increasing) or downward (decreasing) trend. The null hypothesis is a accepted if the estimated median slope $\left(\mathrm{I}_{\text {med }}\right)$ is within the range of $[(n-C / 2)$ and $(n+C a) / 2]$, where $\mathrm{Ca}=Z_{i}-\alpha / z \sqrt{\operatorname{Var}(s)}$ is a standardized Gaussian statistic and is the significance level. $\operatorname{Var}(\mathrm{s})$ is calculated using Equation 3.

\section{Development of IDF equation for Benin city}

The intensity-duration-frequency (IDF) is a frequency relationship among rainfall depth, intensity, and storm duration. They are used in the design of storm management facilities and flooding reservations. The IDF may be constructed by adopting the following steps:

i) Gather time series records of different durations (eg. 5, 10, 15, 20 mins etc.)

ii) Extract annual extremes form the record of each duration

iii) Fit the annual extreme data to a probability distribution in order to estimates rainfall depths for different return periods. The Gumbel's extreme value distribution is used to fit the annual extreme rainfall data.

The Gumbel probability distribution has the following form:

$$
X_{T}=m_{z}+K_{T_{z}}(8)
$$

Where $X_{\mathrm{T}}$ represents the magnitude of the T-year event, $\mu_{z}$ and $\sigma_{z}$ are the mean and standard deviation of the annual maximum series, and $\mathrm{K}_{\mathrm{T}}$ is a frequency factor depending on the return period $(\mathrm{T})$ and also distribution - specific. The frequency factor $\mathrm{K}_{\mathrm{T}}$ for Gumbel's extreme value distribution is given by:

$$
K_{T}=\frac{\sqrt{6}}{\pi}\left[0.5772+\ln \left(\ln \left(\frac{T}{T-1}\right)\right)\right] \text { (9) }
$$

iv) Tabulation of annual maximum series for different durations and application of equation 8 to each duration

v) Calculation of average intensity as follows:

$$
\bar{I}_{T}(D)=\frac{X_{T}}{D}(10)
$$

Where $\mathrm{D}$ is duration.

vi) Construction of IDF curves; plotting rainfall intensity versus duration for different return periods

The IDF curves usually represented by an empirical formula Lam $\&$ Leung, ${ }^{20}$ the Ontario Drainage Management Manual ${ }^{21}$ recommends fitting the IDF data to the three parameter function (Wisner's formula):

$$
I=\frac{C}{(D+a)^{b}}(11)
$$

Where I is the rainfall intensity $(\mathrm{mm} / \mathrm{her})$; $\mathrm{D}$ the rainfall duration (min) and $\mathrm{a}, \mathrm{b}$ and $\mathrm{C}$ are coefficients. After selecting a reasonable value of parameter a, method of least squares is used to estimate the values of $\mathrm{C}$ and $\mathrm{b}$. The calculation is repeated for a number of different values of "a" in order achieve the closest possible fit of the data. The best fit value of coefficient "a" is one with the least error sums of squares.

\section{Derivation of updated equations}

The relationship between estimated rainfall intensity and duration may be expressed according to the Wisner equation as:

$$
I=\frac{C}{(D+a)^{b}}(11)
$$

Where $\mathrm{I}=$ extreme rainfall intensity in $\mathrm{man} / \mathrm{hr}, \mathrm{D}=$ duration in minutes, a,b and C are Wisner's constants which depends on return period and location. The constants were obtained as follows:

(i) Taking Logarithms in both sides of Equation 11, gives a linear equation of the form:

$$
\log I=\log C-b \log (D+a)(12)
$$

The best values of $\mathrm{a}, \mathrm{b}$ and $\mathrm{C}$ are those for which the sum of the squares of these deviations as minimum;

$$
S E E=\sum_{i=1}^{n}[\log I-\{\log C-b \log (D+a)\}]^{2}
$$

The partial differentiation of SEE with respect is $\mathrm{b}$ and $\mathrm{C}$ gives

$$
\begin{gathered}
\quad S \log I=n \log C-b \operatorname{Slog}(D+a)(14) \\
S[\log I \log (D+a)]=\log C \operatorname{Slog}(D+a)-C S[\log (D+a)]^{2}
\end{gathered}
$$

Where $\mathrm{n}$ is the number of observational and all the summations are over all n-value. After obtaining the required summations, Equation 14 and Equation 15 were solved simultaneously to obtain the best values of $\mathrm{b}$ and $\mathrm{C}$ for any assumed values of constant " $\mathrm{a}$ " and the best value of "a" was found by trial and error.

\section{Evaluation of IDF models efficiency}

Efficiency criteria commonly cited in literature for evaluating the performances of hydrologic models were used (e.g) Krause et al., ${ }^{22}$ Alexandris et al., ${ }^{23}$ Raju and Kumar, ${ }^{24}$ The indices used are coefficient 
of determination $\left(\mathrm{R}^{2}\right)$; Mean and Absolute error (MAE), Root Mean Square Error (RMSE), Nash-Sutchiffe Efficiency (NSE), Error Sums of Squares (SEE) and RMSE -observations standard deviation ratio (RSR). The computational forms of the above indices are given below;

Coefficient of determination $R^{2}=\frac{\sum_{i=1}^{N}\left(I_{o}-\overline{1}_{o}\right)\left(I_{p}-\overline{1}_{p}\right)}{\sqrt{\sum_{i=1}^{N}\left(I_{o}-\bar{l}_{o}\right)^{2}} * \sqrt{\sum_{i=1}^{N}\left(I_{p}-\overline{1}_{p}\right)^{2}}}$

$$
\begin{gathered}
M A E=N^{-1} \sum_{i=1}^{N}\left|I_{p}-I_{o}\right| \\
R M S E=N^{-1}\left[N^{-1} \sum_{i=1}^{N}\left(I_{p}-I_{o}\right)^{2}\right]^{1 / 2} \\
S E E=\left[\frac{\left(I_{o}-I_{p}\right)^{2}}{n-2}\right]^{1 / 2}
\end{gathered}
$$

$$
\begin{gathered}
\text { Nash - Sutchiffe Efficiency }=1-\frac{\sum_{i=1}^{N}\left(I_{O}-I p\right)^{2}}{\sum_{i=1}^{N}\left(I_{O}-\overline{1}_{O}\right)^{2}} \\
R S R \frac{R M S E}{S T D E V_{o b s}}=1-\frac{\left[\sum_{i=1}^{N}\left(I_{o}-I_{p}\right)^{2}\right]^{1 / 2}}{\left[\sum_{i=1}^{N}\left(I_{o}-\overline{1}_{o}\right)^{2}\right]^{1 / 2}}
\end{gathered}
$$

Where $\mathrm{N}$ is the sample size, $\mathrm{I}_{\mathrm{o}}$ is the observed rainfall intensity discharge, $\mathrm{I}_{\mathrm{p}}$ is the predicted rainfall intensity. I is the average observed rainfall intensity. $\mathrm{R}^{2}$ statistics is an indication of the explanatory power of the IDF equation, in terms of how the IDF equations approximate or fit the data points. The higher the value of $\mathrm{R}^{2}$, the more successful the fit or the explanatory power, if $\mathrm{R}^{2}$ is small, it indicates a poor fit, possibly to search for an alternative model. $\mathrm{R}^{2}$ lies between 0 (no correlation) and 1 (perfect fit). The Nash-Sutchiffe Efficiency (NSE) lies between 1.0 (perfect fit) and - $\infty$. MAE and RMSE expressed the average differences between Predicted (I $)$ and observed (Io) values around the MBE. RMSE and MAE are among the best overall measures of model performance because they summarized the mean difference between observed (Io) and predicted $\left(\mathrm{I}_{\mathrm{p}}\right)$ values.

SEE quantifies the spread of the data around the regression line and is thus used as measure of goodness of fit. RMSE - observations standard deviation ratio (RSR) is calculated as the ratio of the RMSE and standard deviation of measured data as shown in Equation 21. RSR varies from the optimal value of 0 , which indicates zero RMSE or residual variation and therefore perfect model simulation, to a large positive value. The lower the RSR, the lower the RMSE, and the better the model simulation performance..$^{25}$

\section{Results and discussion}

The main result of this study is provided in Table 1 and Table 2 and Figure 1 and Figure 2.

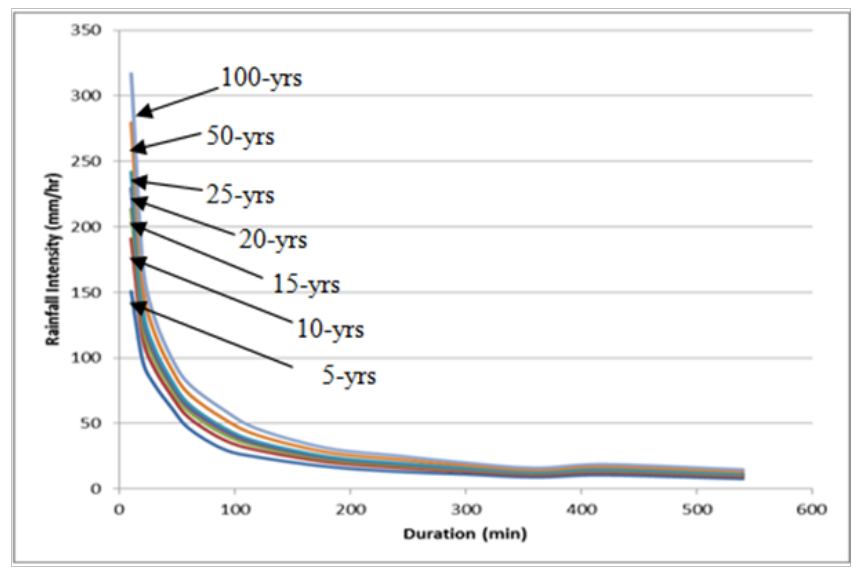

Figure I Rainfall-duration-frequency of Benin city.

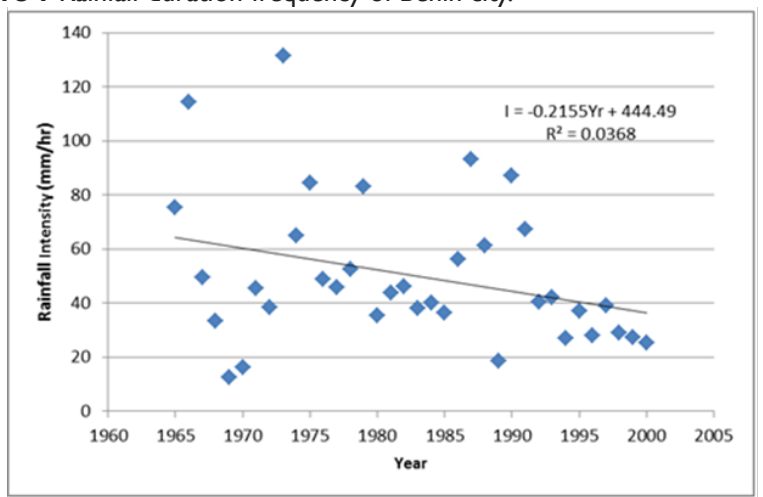

10-Minutes

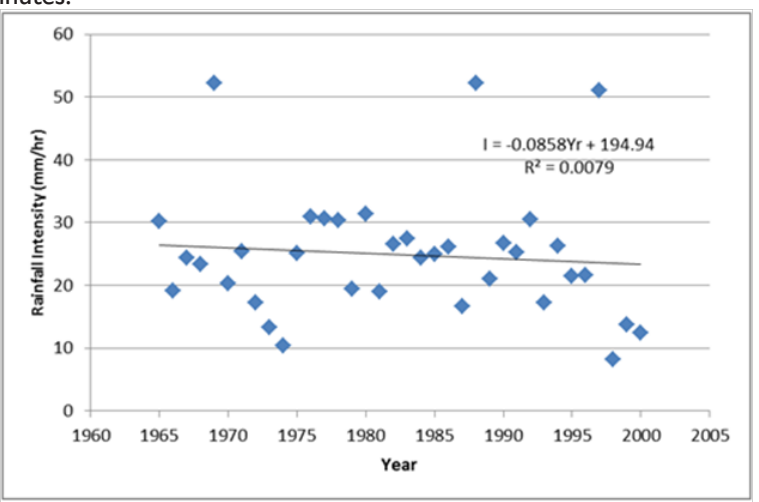

20 - Minutes.

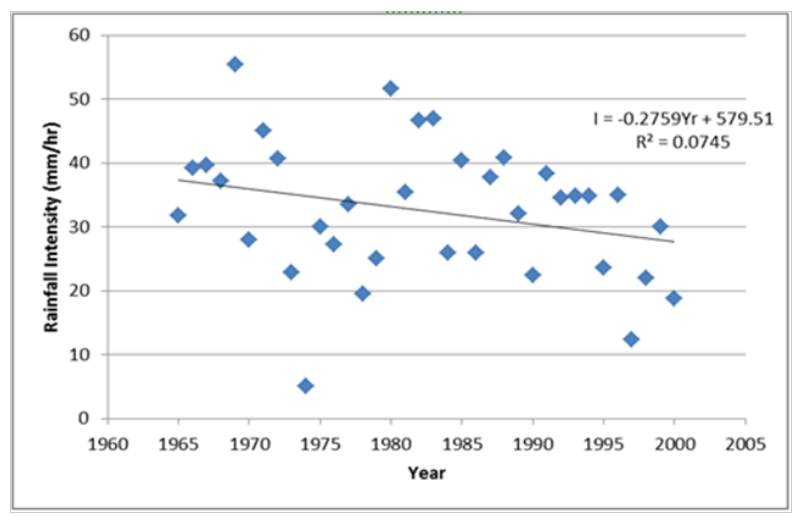

30- Minutes. 


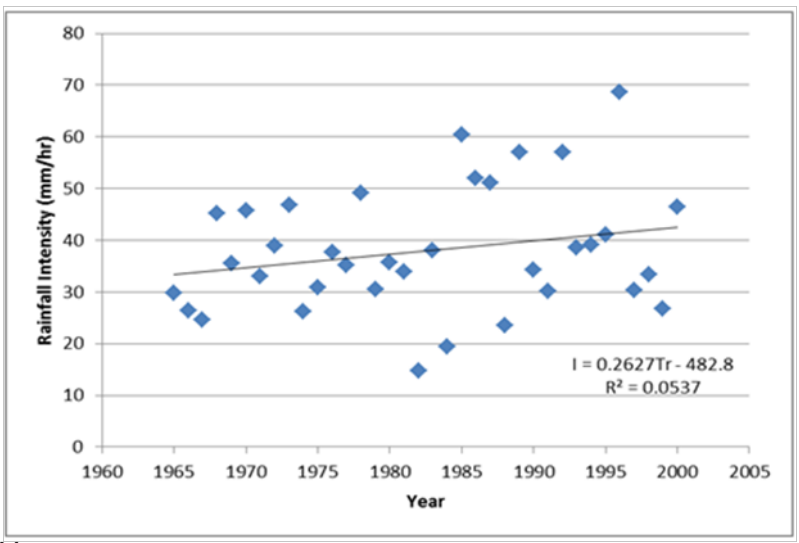

45-Minutes

Figure 2 Rainfall intensity trends for ten - minute, twenty - minute, thirty minute and forty five - minute durations.

\section{IDF equations and efficiency criteria}

Table 1 contains Wisner'contains $a, b$ and $C($ Equation 11) and the efficiency criteria for judging the accuracy of each equation. It is observed that the upper bound for constants " $b$ " is generally less or equal to 5 except for 5 -yr return period which has a constant value of 8 . Figure 1 shows the IDF curves for return period of 5 to 100years. These plots portray the expected logarithmic profile typical of IDF curves. From Table 2 , it is apparent that $\left(\mathrm{R}^{2}\right)$ falls within the inequality $0.40 \leq \mathrm{R}^{2}<0.972$, which implies the strong explanatory power of IDF equations and they fall within the range for $5 \leq \mathrm{T}-\mathrm{yr} \leq 25$. This return period range is usually recommended for the design of urban storm drainage systems. Also the $\mathrm{R}^{2}$ values obtained fall within the acceptable limit. ${ }^{24,25}$ Beyond return period of 25 years, the explanatory power of the IDF may be unsatisfactory. The result obtained for other indices, SEE, RMSE, RSR, MAE and NSE may be represented by the following inequalities ; $2.55 \leq \mathrm{SEE} \leq 4.31 ; 2.34 \leq \mathrm{RMSE} \leq 3.96$; $0.0441 \leq \mathrm{RSR} \leq 0.056 ; 1.93 \leq \mathrm{MAE} \leq 2.95$ and $0.9969 \leq \mathrm{NSE} \leq 0.998$ respectively. Based on these inequalities, the IDF equations are considered excellent according to NSE and RSR indices. ${ }^{24,25}$ The MAE, RMSE and SEE indies also showed better performances due to their lower values.

\section{Rainfall intensity trends}

Table 2 shows the results of trend analyses using Mann-Kendall and Sen's tests. The Mann-Kendall test and Sen's Slope estimator were applied to the rainfall intensity annual time series. The observed Man-Kendall statistics $\left(Z_{m k}\right)$ and Sen's Slope values $(\beta)$ are presented in columns 3 and 9 respectively. These results indicate annual rainfall intensities characterized by negative (downward) trends for rainfall durations of 10 to 30 minutes, while between 45 and 540 minutes, they exhibit both negative (downward) and positive (upward) trends. Figure 2 presents the rainfall intensity plots for durations of $10-45$ minute, The susequent plots are not presented due to lack of space. It is apparent that in column 9, all the durations indicated statistically insignificant trends at 5\% significant level, except for 540 - minutes duration where a statistically significant positive trend was obtained. Extrapolation of future rainfall intensity scenarios could not be performed due to observed insignificant trends. ${ }^{15}$ Furthermore, the statistically insignificant trends obtained for rainfall durations of 10 to 30minutes also corresponds to the inlet time generally applied for computing storm water - flow rates. ${ }^{26}$ and this implies that the impact of climate change on storm water - flow rates is negligible and may not pose flooding risk.

The estimated median slopes fall within the accepted confidence interval. ${ }^{19}$ These findings agrees within similar studies in the region such as Okpara et al. ${ }^{27}$ who studied the possible impacts of climate variability/change and urbanization on water resources availability in the Benin Owena river basin and observed increasing temperaturetrend estimated at $0.37^{\circ} \mathrm{C} /$ decades, high rate of evaporation resulting in increasing water loss in the basin. Oguntunde et al. ${ }^{28}$ also studied rainfall trends in Nigeria $1901-2000$, and found that about $90 \%$ of the entire landscape exhibited negative trends but only $22 \%$ showed significant changes at $5 \%$ significance level. Oguntunde \& Abiodun ${ }^{28}$ studied the impact of the impact of climate change on the Niger River Basin hydroclimatology in West Africa and found that elevated greenhouse gases under A1B scenario would provide a drier climate during the rainy season and a wetter climate during the dry season. They also found that the Nigeria landscape was generally drying since the 1970s with the driest decades occurring between 1970 and 1990 of the $20^{\text {th }}$ century.

Table I IDF equation and efficiency criteria

\begin{tabular}{|c|c|c|c|c|c|c|c|c|c|}
\hline \multirow{2}{*}{$\begin{array}{l}\text { Return } \\
\text { period T-yr }\end{array}$} & \multicolumn{3}{|c|}{ Wisner's constant eq. I I } & \multirow{2}{*}{$\begin{array}{l}\text { Coeff. of } \\
\text { deter } \mathbf{R}^{2}\end{array}$} & \multirow{2}{*}{$\begin{array}{l}\text { Error sums and sqrs. } \\
\mathbf{R}^{2} \operatorname{SEE}(\mathrm{mm} / \mathrm{hr})\end{array}$} & \multirow{2}{*}{$\begin{array}{l}\text { Root mean Sq.Err } \\
\text { (RMSE) }\end{array}$} & \multirow{2}{*}{ RSR } & \multirow{2}{*}{ MAE } & \multirow{2}{*}{ NSE } \\
\hline & $\mathbf{a}$ & $\mathbf{b}$ & C & & & & & & \\
\hline 5 & 0.8925 & 8 & $|955.4|$ & 0.598 & 2.55 & 2.34 & 0.056 & 1.93 & 0.9969 \\
\hline 10 & 0.8552 & 5 & 1886.67 & 0.972 & 2.81 & 2.59 & 0.045 & 2.04 & 0.9975 \\
\hline 15 & 0.8287 & 3 & 1770.45 & 0.564 & 2.8 & 2.57 & 0.0448 & 1.95 & 0.998 \\
\hline 20 & 0.8147 & 2 & 1731.77 & 0.592 & 2.94 & 2.71 & $0.044 I$ & 1.96 & 0.998 \\
\hline 25 & 0.8145 & 2 & $|805.2|$ & 0.5 & 3.17 & 2.92 & 0.0453 & 2.14 & 0.998 \\
\hline 50 & 0.7992 & 0.5 & $|795.2|$ & 0.497 & 3.61 & 3.32 & 0.0449 & 2.33 & 0.998 \\
\hline 100 & 0.7844 & 0.1 & | 909.77 & 0.47 & 4.31 & 3.96 & 0.0476 & 2.95 & 0.998 \\
\hline
\end{tabular}


Table 2 Mann-kendall analysis and sen's slope estimation

\begin{tabular}{lllllllll}
\hline Duratn & S.Statics & Zmk & Za- $\alpha / 2$ & Ho Ca & $(\mathbf{n}-\mathbf{C} \alpha) / \mathbf{2}$ & $\mathbf{( n - C} \alpha) / 2$ & Sen's slope $\boldsymbol{\beta}$ \\
\hline 10 & 0 & -0.01362 & 1.96 & A & 148.864 & -53.93 & 89.93 & -0.005 \\
20 & -58 & 0.776567 & 1.96 & A & 148.864 & -53.93 & 89.93 & -0.123 \\
30 & -133 & 1.798365 & 1.96 & A & 148.864 & -53.93 & 89.93 & -0.304 \\
45 & 97 & 1.307902 & 1.96 & A & 148.864 & -53.93 & 89.93 & 0.254 \\
60 & -135 & 1.825613 & 1.96 & A & 148.864 & -53.93 & 89.93 & -0.354 \\
90 & 135 & 1.825613 & 1.96 & A & 148.864 & -53.93 & 89.93 & 0.487 \\
120 & 144 & 1.948229 & 1.96 & A & 148.864 & -53.93 & 89.93 & 0.533 \\
180 & 62 & 0.821063 & 1.96 & A & 148.864 & -53.93 & 89.93 & 0.1898 \\
240 & 4 & 0.040872 & 1.96 & A & 148.864 & -53.93 & 89.93 & 0.0005 \\
300 & -16 & 0.20436 & 1.96 & A & 148.864 & -53.93 & 89.93 & -0.0644 \\
360 & 110 & 1.485014 & 1.96 & A & 148.864 & -53.93 & 89.93 & 0.3593 \\
240 & 58 & 0.776567 & 1.96 & A & 148.864 & -53.93 & 89.93 & 0.3581 \\
540 & -152 & 2.057221 & 1.96 & A & 148.864 & -53.93 & 89.93 & -0.7072 \\
\hline
\end{tabular}

\section{Future IDF projections and urban drainage}

The study is undertaken with the main objective of accessing the impact of climate change on drainage system for Benin City Nigeria. The results obtained show that short duration rainfall intensities have insignificant downward (negative) trends which implies that climate change will negligible negative impacts on urban flooding. In this regard, the extrapolations could not be performed since the observed trends are statistically insignificance. ${ }^{15,29}$ It was observed that rainfall intensities have insignificant downward (negative) trends meaning that climate change will have negligible negative impacts on flooding. This finding agrees with Carlier and Elkhattabi, ${ }^{30}$ who compared IDF curves before and after 1980 for the City of Toronto, Canada and observed similar downward (negative) trends after 1980, especially for short duration rainfall intensities. They also compared their findings with those obtained by other authors (for example Akbari et al., ${ }^{31}$ ) and concluded that impact of global warming is geographical location - specific and it is not possible to draw some general guidelines across the globe.

\section{Conclusion and recommendation}

It is commonly recognized that climate change will have significant impact on the water cycle and precipitation pattern. ${ }^{32}$ In some regions such changes are expected to entail increase in the frequency and intensity of precipitation extremes thus leading to increased risk of flooding. ${ }^{8}$ In the case of Benin City Nigeria, this study indicates an insignificant downward (negative) trends in intensities for the short duration periods less or equal to 30 minutes, meaning that climate change will not pose the anticipated adverse risk of flooding. This implies that the current drainage capacities will meet the need for the future, assuming the observed trend persists. This finding also agreed with. ${ }^{10}$ who asserted that the signatures in rainfall extremes do not necessarily imply the use of nonstationary IDFs for design considerations. Despite the observed trend, there is need for efficient management of urban drainage infrastructure. Consequently this study strongly recommends the application of urban drainage simulation tools such as the SWMM model. SWMM is a dynamic rainfall runoff simulation tools used for single events or long term (continue) simulation of runoff quantity and quality from primarily urban areas. ${ }^{33,34}$

\section{Acknowledgments}

None.

\section{Conflicts of interest}

The authors declare that there is no conflict of interest.

\section{References}

1. Condon LE, Gangopadhuyay S, Pruitt T. Climate change and nonstationary flood risk for the upper Truckee River basin. Hydrology and Earth System Science. 2015;19:159-175.

2. Wang X, Hjuand G, Liu J. Projected Increases in Intensity and frequency of rainfall extremes, through a regional climate modeling approach. $J$ Geophys Res Atmos. 2014;119:13271-13286.

3. Koutsoyiannis D, Kononis D, Manetas A. A mathematical framework for studying rainfall intensity - duration-frequency relationships. $J$ hydrol. 1998;206(1-2):18-135.

4. Loughlin G, Huber W, Chocat B. Rainfall-Runoff Processes. Journal of hydraulic Research. 1996;34(6):733-751.

5. Wolcott SB, Mroz M, Basile J. Application of Northeast Regional Climate Centre Research results for the purpose of evaluating and updating Intensity -Duration -Frequency (IDF) Curves" Case Study: Rochester, New York. In: Proceedings of world environmental and water resources congress 2009. Kansas City, Missouri. 2009.

6. Bell F. Generalized Rainfall intensity -Duration-Frequency (IDF) Relationship. Proceedings, ASCE, 95, HY1. 1969;311-327.

7. Bilham EM. Classificationof heavy falls in short periods. British Rainfall. 1935;76:262-280.

8. Mailhot A, Duchesne S. Design Criteria of Urban Drainage Infrastructures under Climate Change. Journal of Water Resources Planning and Management. 2010;136(2):201-208.

9. Bayazit M. Nonstationarity of Hydrological Records and Recent Trends in Trend Analysis: A State-of-the-art Review. Envron Process. 2015;2(3):527-542.

10. Ganguli P, Coulibly P. Does Nonstationarity in Rainfall Require Nonstationary Intensity-Duration-Frequency Curves. Hydrology and Earth System Science. 2017;21:6461-6483.

11. Prodanovia, Simonovic. Development of Rainfall Intensity-DurationFrequency Curves for the City of London under the Changing Climate. 
Water Resources Research Report, No:058; ISBN(PRINT) 978-07714-2667-4. 2007;1-51.

12. CSA (Canadian Standards Association) Technical Guide-Development, Interpretation and Use of Rainfall Intensity-duration-frequency (IDF) Information: Guideline for Canadian Water Resources Practitioners, CSA Group, Ottawa. 2010.

13. Goore Bi E, Gachon P, Vrac M, et al. Which downscaled rainfall data for climate change impact studies in urban areas? Review of current approaches and trends. Theor Appl Climatol. 2015;127(3-4):685-699.

14. Olsson J, Amaguchi H, Alsterhag E, et al. Adaptation to climate Change Impacts on urban storm water: a case study in Arvika, Sweden. Climate change. 2013;116(2):231-247.

15. Denault C, Millar RG, Lence BJ. Assessment of Porrible Impacts of Climate change in an Urban Catchment. Journal of American Water Resources Association. 2006;42(3):685-697.

16. Guo Y. Updating rainfall IDF relationship to maintain urban drainage design standards. J Hydrol Engineering. 2006;11(5):506-509.

17. Douglas EM, Vogel RM, Kroll CN. Trends in floods and Low flows in the United States: Impact of Spatial Correlation. Journal of hydrology. 2000;240(1-2):90-105.

18. Fritsch E Casey. Evaluation of Flood in Response to Climate Variability. Master of Science thesis, Michigan Technological University. 2012.

19. Ndione DM, Sambou S, Sane MS, et al. Statistical Analysis for Assessing Randomness, Shift and Trend in Rainfall Time series under Climate Variability and Change: Case of Senegal. Journal of Geoscience and Environment Protection. 2017:5:31-51.

20. Lam CC, Leung YK. Extreme Rainfall Statistics and design of Rainstrom Profile of selected Locations in Hong Kong (Technical Note No.86). Royal Observatory, Hong Kong. 1994;89.

21. MTO, MTO Drainage management manual. Drainage and Hydrology Section. Ministry of Transportation, Ontario, Canada. 1997.

22. Krause P, Boyle DP, Base F. Comparison of different efficiency criteria for hydrological model assessment. Advance in Geoscience. 2005;5:89 97.

23. Alexandris S, Stucevic R, Petkovic S. Comparative analysis of reference evapotranspiration from the service of rain fed grass in Central Serbia, calculated by six empirical methods against the Perman Monteith formula. European Water. 2018;21(22):17-28.

24. Raju SK, Kumar. Impact of climate Change on Water Resources, with Modeling Techniques and Case Studies. Springer Nature Singapore pte Ltd. 2018.

25. Moriasi DN, Arnold JG, Van Liew MW, et al. Model evalutionguildline for systematic Quantification of Accuracy in Watershed Simulation. Trans, ASABE. 2007;50(3):885-901.

26. Water resources handbook. Larry W Mays, editor-in-chief, McGrawHill, ISBN 0-07-041150-6. 1996.

27. Okpala JN, Akeh LE, Anufforom. Possible Impacts of Climate Variability/Change and Urbanization on Water Resources availability and quality in the Benin-Owena River Basin. Climate Variability and Change-Hydrological Impacts. (Proceedings of the Fifth FRIEND World Conference held at Havana Cuba, November, 2006), IAHS Public. 2006;1-7.

28. Oguntunde PG, Abiodun BJ, Lischcia G. Rainfall Trends in Nigeria 1901 - 2000. Journal of Hydrology. 2011;411(3-4):207-218.

29. Denault C, Miller RG, Lence BJ. Climate Change and Drainage Infrastructure Capacity in an Urban Catchment. Annual Conf of the Canadian Society for Civil engineering. 2002;5-8.

30. Erick Carlier, Jamal El-khattabi. Impact of global warming on intensity duration frequency (IDF) relationship of precipitation: a case study of Toronto Canada. Open Journal of Hydrology. 2016;6:1-7

31. Akbari H, Rakhshandehroo GR, Afrooz AH, et al. Climate Change Impact on Intensity -Duration-Frequency curves in Chenar - Rahdar River Basin. Watershed Management. 2015;48-61.

32. Zhou Q, Arnbjerg-Nielsen K, Mikkelsen PS, et al. Urban drainage design and climate change adaptation decision making. Kgs. Lyngby: DTU Environment. 2012;1-95.

33. Philip G, Oguntunde, Babatunde JA. The Impact of Climate Change and the Niger River Basin Hdroclimatology. West Africa Clim Dyn. 2013;40(1-2):80-94.

34. Sofia E. Updating Rainfall Intensity-Duration-Frequency Curves in Sweden Accounting for the Observed Increase in Rainfall Extremes. Program for Air Water and Landscape Science, Uppsala University, Villavagen 16, SE-751-05, Uppsala, ISSN 1401-5765. 2016;1-49. 